\title{
RAS Protein and its Regulators in Hamster Sperm Function
}

\author{
Subir K Nagdas ${ }^{1 *}$, Wallace $\mathrm{S}^{1}$, Rahman $\mathrm{R}^{1}$, Eaford $\mathrm{D}^{1}$, and Raychoudhury $\mathrm{S}^{2}$ \\ ${ }^{1}$ Department of Chemistry, Physics \& Materials Science, Fayetteville State University, USA \\ ${ }^{2}$ Department of Biology, Chemistry and Environmental Health Science, Benedict College, USA
}

*Corresponding author: Subir K Nagdas, Department of Chemistry and Physics, Fayetteville State University, 1200 Murchison Road, Fayetteville, NC 28301, USA, Tel: 910-672-2073; Fax: 910-672-2420; Email: snagdas@uncfsu.edu

\section{Research article \\ Volume 5 Issue 3}

Received Date: October 14, 2020

Published Date: November 20, 2020

DOI: $10.23880 /$ ijbp-16000186

\section{Abstract}

Spermatozoa entering the epididymis have no capacity for protein synthesis, are incapable of forward motility, and have no fertilizing ability. During post-testicular maturation in the epididymis, the sperm surface undergoes extensive remodeling, and this physiological process plays a critical role in the development of the fertilization-competent spermatozoon.

Previously, we identified farnesyltransferase (FTase), an enzyme which functions in post-translational protein lipidation in hamster epididymal spermatozoa. In addition, we have identified the signaling protein RAS, a FTase substrate, in a plasma membrane (PM) fraction. Immunoblot analysis of sperm plasma membrane fractions demonstrated the presence of PI3Kinase, a downstream target of RAS. Coimmunoprecipitation (Co-IP) analysis demonstrated the interaction of PI3-Kinase with RAS. Does the protein lipidation play a significant role in the development of the fertilization-competent spermatozoon? The objectives of the present study included the biochemical localization of FTase and the identification and characterization of RAS upstream and downstream effectors in hamster spermatozoa. First, we examined if FTase is localized to soluble or particulate fractions of caput and cauda epididymal spermatozoa. Immunoblot analysis revealed that FTase is localized to the soluble fraction of both caput and cauda epididymal spermatozoa. Subsequent studies were performed to identify potential upstream and downstream effectors of RAS. Immunoblot analysis of sperm PM fractions demonstrated the presence of the upstream effector (GRB2) and the downstream effectors (RAF-Kinase). Immunofluorescence with anti-RAF-Kinase polyclonal antibody localized RAF- Kinase to the sperm connecting piece and flagellum. Coimmunoprecipitation analysis revealed the interaction of RAF-Kinase with RAS. The fate of RAS and its downstream effectors (PI3-Kinase and RAF-Kinase) was examined during capacitation of hamster cauda epididymal spermatozoa. RAS and its downstream effectors (PI3-Kinase and RAFKinase) remain anchored to the sperm pellet after the completion of capacitation. The interaction of RAS with RAF-Kinase suggests that RAS may regulate several signaling pathways in spermatozoa.

Keywords: RAS, Sperm; Signal Transduction; Sperm capacitation

\section{Introduction}

The functionally mature spermatozoon is the product of two developmental processes: spermiogenesis in the testis and post-testicular maturation in the epididymis $[1,2]$. Spermatozoa entering the epididymis have little, or no, capacity for protein synthesis, and they are incapable of forward motility or of fertilizing an egg $[1,3]$. During posttesticular maturation in the epididymis, the sperm surface undergoes extensive remodeling that includes the binding of epididymal secretory proteins to restricted surface domains and the redistribution of pre-existing proteins, usually 


\section{International Journal of Biochemistry \& Physiology}

accompanied by proteolytic processing, to a final residence domain [4-7]. This membrane reorganization appears crucial to the development of functional capacity of sperm. How most of these changes result in a mature, functional spermatozoon is poorly understood.

One mechanism, which functions in targeting proteins to specific cellular membranes in somatic cells, is posttranslational lipidation [8]. Prenylation represents one class of enzyme-catalyzed lipidation in which a 15-carbon containing farnesyl or a 20-carbon containing geranylgeranyl residue is covalently added to protein substrates with a C-terminus "CAAX" motif [9-11]. The enzymes, which catalyze prenylation, farnesyltransferase (FTase) and geranylgeranyl transferase type I, each recognize distinct protein substrates based on the amino acid sequence of the CAAX motif $[10,12,13]$. Substrates of FTase include nuclear lamins, a peroxisome membrane protein, and RAS, a mediator of several signal transduction pathways [9-11,14]. RAS plays a significant role in cell fate. Prenylated, membrane-bound RAS requires activation before it exerts a downstream signaling function, and in somatic cells, its activation is coupled to cell surface receptors tyrosine kinases or heterotrimeric G-protein coupled receptors [14-16]. Membrane-bound RAS functions as binary switches that cycles between an inactive GDP-bound and an active GTP-bound states. The activated state of RAS is promoted by guanine nucleotide exchange factors, which stimulate GTP loading, and also by GTPase activating proteins that increase GTP hydrolysis and conversion to a GDP bound state [12,16-21]. GTP-RAS binds specific effector proteins resulting in their activation and function in signaling pathways. Effectors activated by GTP-RAS include: the serine/threonine kinase RAF-Kinase, Protein Kinase C, and phosphatidylinositol 3-kinase (PI3Kinase) [16,18,21-25]. Thus, it is well established that RAS activates a hierarchical cascade of intersecting pathways which modulate several biological functions.

We have shown the presence of RAS in a plasma membrane (PM) fraction from hamster cauda epididymal spermatozoa [26]. RAS is localized to the sperm flagellum using a Pan-RAS antibody [26]. Immunoblot analysis of sperm PM fractions demonstrated the presence of PI3-Kinase, the downstream target of RAS, and coimmunoprecipitation analysis demonstrated the interaction of PI3-Kinase with RAS [26]. Further studies demonstrated that inhibitors of PI3-Kinase inhibited the hyperactivation of sperm motility during capacitation, suggesting that PI3-Kinase is associated with development of this motility pattern [26]. Previously, we have demonstrated the presence of farnesyltransferase (FTase) in the cytoplasmic droplet of epididymal spermatozoa [27]. In addition, our identification of RAS in a PM fraction of cauda epididymal spermatozoa [26] suggests that FTase may function in the assembly of domain-specific signaling pathways. While these data suggest that RAS may participate in signaling pathways of mature spermatozoa, the RAS effectors in spermatozoa have not yet been identified extensively, and the role of RAS signaling pathways in mammalian sperm functions are limited. The present study was focused to determine if FTase is cytosolic or bound to specific polypeptides in the particulate fraction of epididymal spermatozoa and to identify and characterize the activators and effectors of RAS in hamster spermatozoa.

\section{Materials and Methods}

\section{Antibodies}

Mouse monoclonal antibodies including Pan-RAS and anti-PI3-Kinase p85 alpha antibody, were purchased from ThermoFisher Scientific and ABCAM, respectively. Rabbit polyclonal antibodies of GRB2 and FTase $\beta$ and phosphotyrosine monoclonal antibody (pY20) were obtained from ThermoFisher Scientific. Rabbit polyclonal antibody of RAF-Kinase from Sigma-Aldrich was used. Horseradish peroxidase-conjugated, affinity-purified, goat anti-mouse IgG, and goat anti-rabbit IgG secondary antibodies were obtained from KPL Inc., Gaithersburg, MD. All other chemicals were from Sigma Chemical Company.

\section{Animals}

Mature male golden hamsters were housed in the Benedict College (Columbia, SC). Animal Care Facility on a 14L: 10D cycle and given free access to food and water. Care and use of animals conformed to NIH guidelines for humane animal care and use in research, and all protocols were approved by the institutional Animal Care, and Use Committee and the University veterinarians who supervised animal care. Animals were sacrificed by $\mathrm{CO}_{2}$ asphyxiation, and tissues were immediately removed for the protocols described below.

\section{Sperm Preparation}

The caput and cauda epididymes were dissected and minced in calcium-free Tyrode solution at $37^{\circ} \mathrm{C}$. The sperm suspension was centrifuged at $100 \times \mathrm{g}$ for $1 \mathrm{~min}$ to sediment tissue fragments, and the supernatant fluid was recentrifuged at $1,500 \times \mathrm{g}$ for $10 \mathrm{~min}$ at $4^{\circ} \mathrm{C}$. Sperm pellets were used in the extraction and fractionation protocols described below.

\section{Isolation of Plasma membrane from Cauda Epididymal Spermatozoa}

Spermatozoa were suspended in TNI $(150 \mathrm{mM} \mathrm{NaCl}$, $25 \mathrm{mM}$ Tris- $\mathrm{HCl},(\mathrm{pH} 7.5), 2 \mathrm{mM}$ benzamidine, $1 \mu \mathrm{g} / \mathrm{mL}$ 


\section{International Journal of Biochemistry \& Physiology}

leupeptin, $1 \mu \mathrm{g} / \mathrm{mL}$ pepstatin, and $0.05 \%$ sodium azide), disrupted by nitrogen cavitation at 400 psi for $10 \mathrm{~min}$, and pelleted by centrifugation at $1500 \mathrm{X} \mathrm{g}$ for $10 \mathrm{~min}$ at $4^{\circ} \mathrm{C}$. Aliquots of the supernatant fluid $(8 \mathrm{ml})$ containing plasma membrane vesicles were layered on discontinuous sucrose gradients composed of $2 \mathrm{ml} 20 \%$ sucrose and $2 \mathrm{ml} \mathrm{50 \%}$ sucrose; all sucrose solutions contained $150 \mathrm{mM} \mathrm{NaCl}$ and $25 \mathrm{mM}$ Tris- $\mathrm{HCl},(\mathrm{pH} 7.5)$. The gradients were centrifuged at 25,000 rpm for $1 \mathrm{hr}$ in an SW40 rotor (Beckman). The plasma membranes at the 20\%-50\% interface were collected, diluted with TNI, and pelleted by centrifugation at $100,000 \mathrm{Xg}$ for 30 min in a TL55 rotor (Beckman) [26]. Protein was estimated by the method of Bradford [28].

\section{Preparation of Cell Fraction for Western Blot Analysis}

To prepare soluble and particulate fractions, caput and cauda epididymal spermatozoa were suspended in TNI and sonicated for four 10-sec intervals with a Branson sonifier at a medium power setting. The sonicated suspensions were centrifuged at 100,000 X g for $30 \mathrm{~min}$ in a TL55 rotor (Beckman).

A detergent-soluble fraction of spermatozoa was prepared by extraction with $0.1 \%$ Triton X-100 in TNI for 1 hr at $4^{\circ} \mathrm{C}$, followed by centrifugation at $12,000 \mathrm{Xg}$ for $10 \mathrm{~min}$.

\section{Gel Electrophoresis and Western Blotting}

Polypeptides were separated by SDS-PAGE [29] on a $12 \%$ separation gel prepared with a 30:0.8 acrylamide: bisacrylamide ratio. Polypeptides were stained with Coomassie Blue [30]. Western blots were prepared on polyvinylidene difluoride membranes for immunoblot analysis [31].

Immunoblots were blocked with TBS $(0.15 \mathrm{M} \mathrm{NaCl}, 20$ $\mathrm{mM}$ Tris-HCl Buffer, pH 7.5) containing 0.1\% Tween 20, and $1 \%$ BSA for $1 \mathrm{hr}$ and then were incubated with primary antibodies or nonimmune IgG diluted in TBS containing $0.1 \%$ Tween 20 (TBS-TW) and 1\% BSA for one hr. After three washes in TBS-TW, the blots were incubated in an affinity-purified, peroxidase-conjugated secondary antibody (KPL Inc., Gaithersburg, MD) diluted in TBS-TW for $1 \mathrm{hr}$; following several TBS-TW washes, immunoreactive bands were identified by enhanced chemiluminescence using SuperSignal (Pierce) and detected on Kodak BioMax film.

\section{Immunocytochemistry}

Sperm suspension of cauda epididymis were fixed for 1 hr on ice with $4 \%$ formaldehyde and $0.25 \%$ glutaraldehyde in $0.1 \mathrm{M}$ sodium phosphate buffer, $\mathrm{pH}$ 7.4, attached to poly-
L-lysine coated coverslips, and then permeabilized in $-20^{\circ} \mathrm{C}$ acetone for $10 \mathrm{~min}$. Cells were rinsed in TNT $(0.15 \mathrm{M} \mathrm{NaCl}$, $20 \mathrm{mM}$ Tris- $\mathrm{HCl}, \mathrm{pH}$ 8.0, 0.05\% Tween 20), blocked in TNT containing 5\% normal donkey serum and $2.5 \%$ BSA for $1 \mathrm{hr}$, and then incubated with equal dilutions of anti-RAF-Kinase or nonimmune IgG in blocking solution for $1 \mathrm{hr}$. Coverslips were then rinsed three times in TNT containing 1\% goat serum and then incubated in an affinity-purified CY3-donkey antirabbit IgG secondary antibody (Jackson ImmunoResearch, West Grove, PA) diluted in blocking solution for one hr. Following several washes in TNT, the slides were examined by epifluorescence and phase contrast microscopy.

\section{Capacitation}

A population of highly motile cauda epididymal spermatozoa was prepared using a swim-up procedure [32]. Fifty microliters of epididymal contents, obtained by puncturing the cauda epididymis, was placed in a $12 \times 75$ $\mathrm{mm}$ tube and overlain with $2 \mathrm{ml}$ of warm $\left(37^{\circ} \mathrm{C}\right)$ Tyrode medium (TALP-7) containing $0.3 \%$ BSA (fraction V), $0.1 \mathrm{mM}$ hypotaurine, $0.02 \mathrm{mM}$ D-penicilamine, and $1 \mu \mathrm{M}$ epinephrine $[33,34]$ and incubated for $5 \mathrm{~min}$ at $37^{\circ} \mathrm{C}$. The upper 0.5 $\mathrm{ml}$ containing the swim-up spermatozoa, was collected, adjusted to $1 \times 10^{6}$ spermatozoa $/ \mathrm{ml}$, and then capacitated at $37^{\circ} \mathrm{C}$ for $3 \mathrm{hrs}$ in a humidified incubator in a $5 \% \mathrm{CO}_{2}: 95 \%$ air atmosphere. The sperm motility pattern and acrosomal integrity were evaluated by phase contrast microscopy. Based on the motility pattern, the spermatozoa were categorized into two groups: motile spermatozoa exhibiting any flagellar movement and hyperactivated spermatozoa exhibiting a whiplash-like flagellar movement with large-amplitude, asymmetric flagellar bends. Approximately, $80 \sim 90 \%$ of the total spermatozoa population exhibited flagellar movement, and $\sim 50 \%$ of the motile, capacitated spermatozoa exhibited hyperactivated motility; most of the remaining spermatozoa displayed a linear or circular motility pattern. Equal numbers $\left(10^{7}\right.$ cells $)$ of capacitated and noncapacitated spermatozoa were pelleted by centrifugation at 12,000 X g for $5 \mathrm{~min}$ and used for SDS-PAGE, followed by Western blot analyses.

\section{Immunoprecipitation}

For coimmunoprecipitation experiments, cauda sperm plasma membranes were extracted in $0.1 \%$ Triton X-100 in TNI for $1 \mathrm{hr}$ at $4^{\circ} \mathrm{C}$, followed by centrifugation at 100,000 $\mathrm{X} \mathrm{g}$ for $30 \mathrm{~min}$ in a TL55 rotor (Beckman). To remove endogenous IgG, the supernatant fraction was incubated with Protein A-Sepharose beads at $4^{\circ} \mathrm{C}$ for $15 \mathrm{~min}$ and centrifuged at $12000 \mathrm{Xg}$ for $1 \mathrm{~min}$. The supernatant was then incubated with anti-RAS monoclonal antibody for two hrs at $4^{\circ} \mathrm{C}$, and the immune complex was recovered by incubation with Protein G-Sepharose beads for $1 \mathrm{hr}$ at $4^{\circ} \mathrm{C}$. The beads containing the immune complex were washed three times 


\section{International Journal of Biochemistry \& Physiology}

by centrifugation in TNI. Immunoprecipitated proteins were analyzed by SDS-PAGE, followed by Western blotting to identify coprecipitating effector proteins.

\section{Results}

\section{Biochemical Fractionation of Sperm FTase $\beta$}

The distribution of FTase $\beta$ in the soluble and particulate fractions of hamster caput and cauda epididymal spermatozoa was examined by Western blot analysis (Figure 1). The $45 \mathrm{kDa}$ FTase $\beta$ was present in both the total caput (lane 1) and cauda (lane 4) sperm lysates and the caput (lane 2) and cauda (lane 5) soluble fractions. However, FTase $\beta$ was not present in the caput (lane 3) and cauda (lane 6) particulate fractions. This result revealed the localization of FTase $\beta$ to the soluble cell fraction, suggesting that specific barriers may maintain the restricted localization of FTase in spermatozoa.

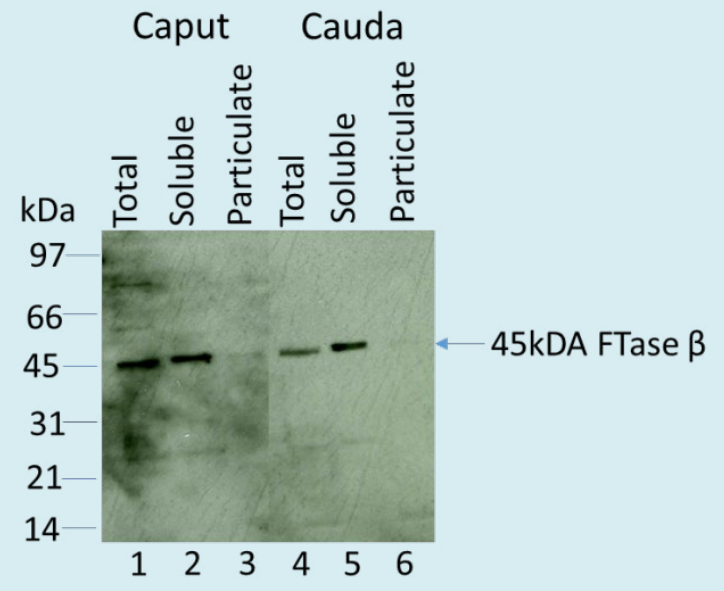

Figure 1: Western blot analyses immunostained with antiFTase $\beta$ showing total sperm lysate (lanes 1 and 4 ), and, the soluble (lanes 2 and 5) and particulate (lanes 3 and 6) fractions of sonicated of caput (lanes 1,2, and 3) and cauda $(4,5$, and 6$)$ epididymal spermatozoa. Each lane of caput and cauda represents cell fractions obtained from 2 $\mathrm{X} 10^{6}$ spermatozoa. FTase $\beta$ is only present in the soluble fraction of both caput and cauda epididymal spermatozoa.

\section{Identification of Upstrem and Downstream Effectors of RAS}

Previously, we have shown the presence of $85 \mathrm{kDa}$ regulatory subunit of PI3-Kinase and $72 \mathrm{kDa} \mathrm{PKC} \zeta$, the downstream targets of RAS, in hamster cauda sperm epididymal plasma membrane fraction [26]. In the present study, we have examined the presence of other known activators and effectors of RAS (Figure 2). Immunoblots of an enriched plasma membrane fraction of hamster cauda sperm epididymal spermatozoa showed the presence of $30 \mathrm{kDa}$ GRB2 (lane 2) and 81kDa RAF-Kinase (lane 3). As shown in lane 1 , a $21 \mathrm{kDa}$ immunoreactive RAS was present in the plasma membrane fractions. An identical lane, stained with nonimmune mouse IgG, showed no immunoreactive bands (data not shown). These data demonstrate the presence of GRB2, an upstream effector of RAS and RAF-Kinase, a downstream effectors of RAS in hamster cauda epididymal spermatozoa.

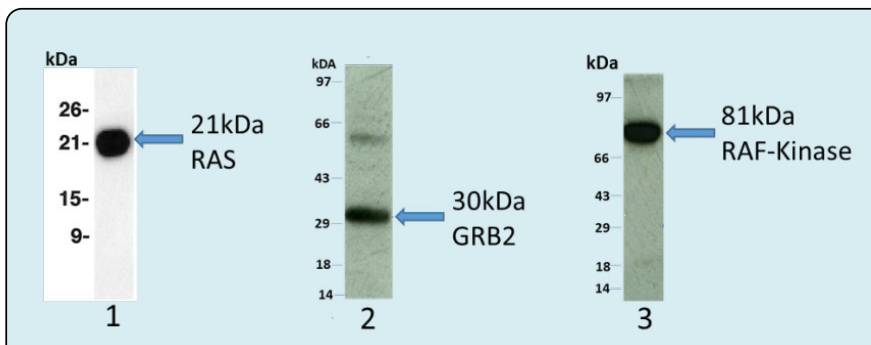

Figure 2: Immunoblot analyses of the plasma membrane fraction separated by SDS-PAGE on a $12 \%$ gel. $15 \mu \mathrm{g}$ of protein was loaded in each lane. Lane 1, 21kDa RAS, immunostained with anti- Pan-RAS; lane 2, 30kDa GRB2, immunostained with anti-GRB2; lane 3, 81kDa RAFKinase, immunostained with anti-RAF-Kinase.

\section{Immunofluorescence Localization of RAF Kinase}

Cauda epididymal spermatozoa immunostained with anti-RAF-Kinase polyclonal antibody exhibited specific staining of the connecting piece and flagellum (Figure 3A). Sperm stained with nonimmune rabbit IgG exhibited no fluorescence of the flagellum and connecting piece (Figure 3B).

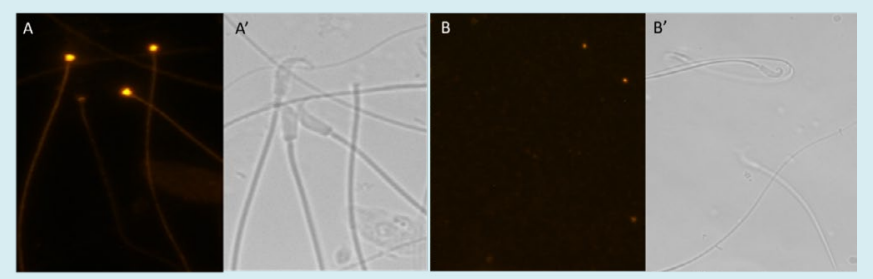

Figure 3: Fluorescence (A and $B$ ) and matched phase contrast $\left(\mathrm{A}^{\prime}\right.$ and $\left.\mathrm{B}^{\prime}\right)$ microscopic examination of hamster cauda epididymal spermatozoa immunostained with anti-RAF Kinase polyclonal antibody (A) and with nonimmune IgG (B). Note the specific fluorescence of the sperm connecting piece and flagellum stained with antiRAF-Kinase (A). Sperm incubated with nonimmune IgG exhibited no fluorescence (B). 


\section{International Journal of Biochemistry \& Physiology}

\section{Identification of RAS-RAF Kinase Interaction by Coimmunoprecipitation Analysis}

A coimmunoprecipitation experiment was performed to examine the interaction of RAS with the effector protein RAF-Kinase. As shown in Figure 4A, 21kDa RAS was completely recovered in the anti-RAS immunoprecipitation pellet (lane 2); both the heavy (50kDa) and light $(25 \mathrm{kDa})$ chains of IgG are evident. When an identical lane of the RAS immunoprecipitation pellet was stained with nonimmune IgG, it revealed only the heavy (50kDa) and light $(25 \mathrm{kDa}) \operatorname{IgG}$ chains but not the RAS band (Figure 4A, lane 3 ). The $81 \mathrm{kDa}$ RAF-Kinase coprecipitated with RAS (Figure 4B, lane 2). In addition, the $50 \mathrm{kDa}$ heavy and $25 \mathrm{kDa}$ light $\mathrm{IgG}$ chains are visible in the IP pellet (Figure 4B, lane 2).

Our co-immunoprecipitation analysis demonstrates the interaction of RAS and RAF-Kinase in hamster cauda epididymal spermatozoa.

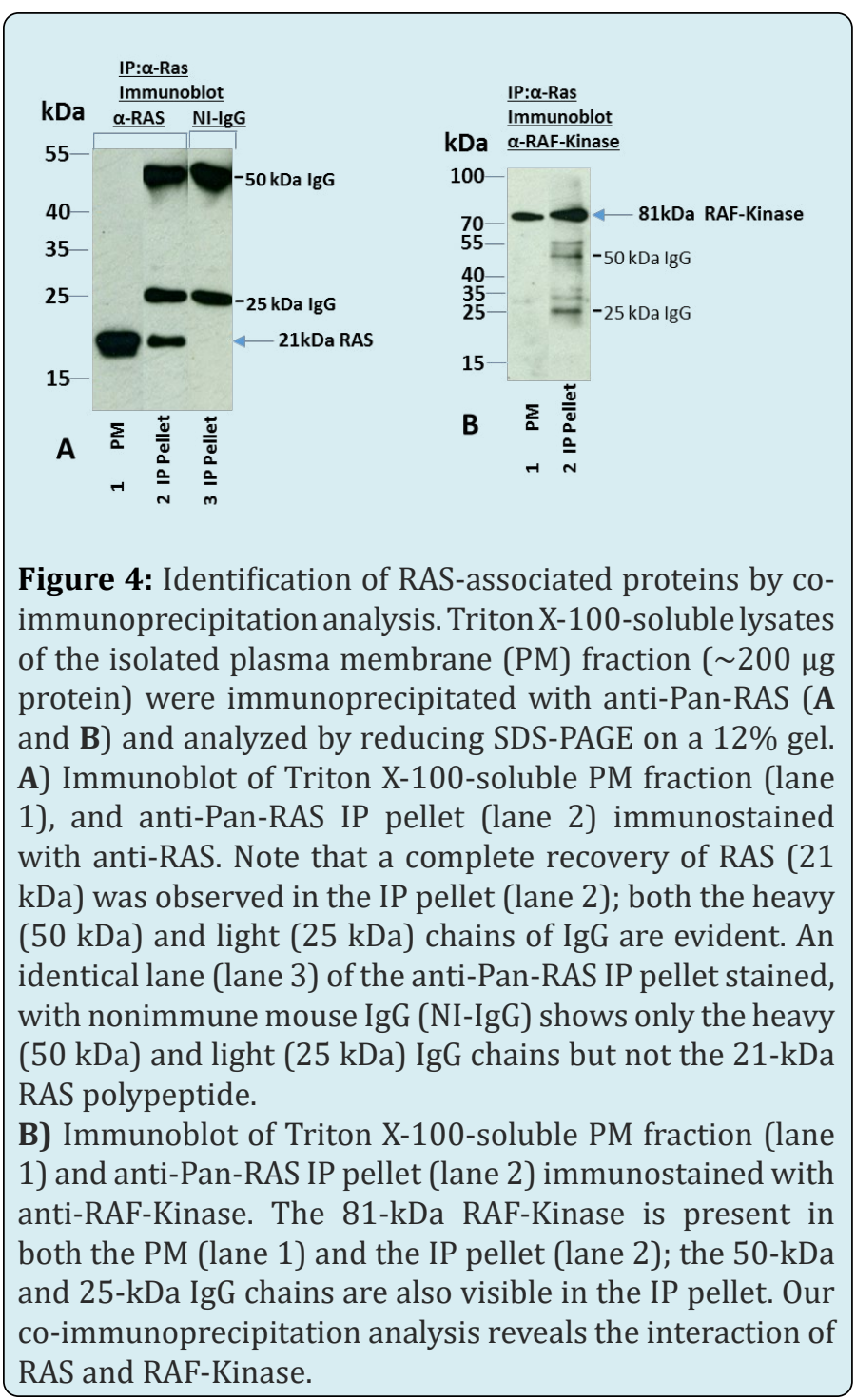

\section{Fate of RAS and its downstream effectors (PI3- Kinase and RAF-Kinase) During Capacitation}

In the present study, we have examined whether RAS and its downstream effectors (PI3-Kinase and RAF-Kinase) are retained or released following capacitation. Protein tyrosine phosphorylation is a key biochemical event accompanying sperm capacitation [35-41]. To examine the efficacy of our capacitation protocol, we analyzed our capacitated sperm fraction with immunoblots stained with $\alpha$-phospho-tyrosine antibody (Figure 5, lane 4).

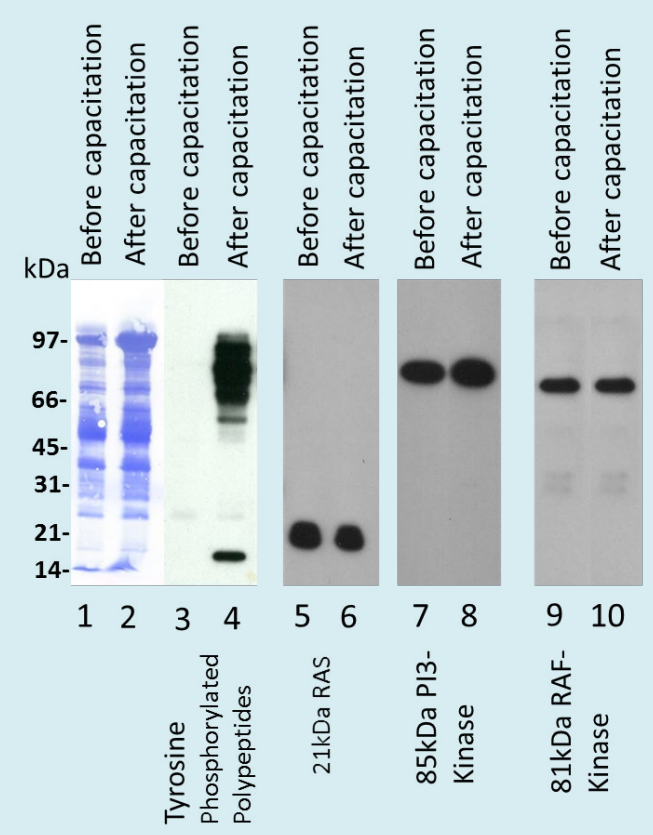

Figure 5: Western blots of noncapacitated (lanes 1, 3, 5, 7, and 9) and capacitated (lanes 2, 4, 6, 8, and 10) spermatozoa fractionated by reducing SDS-PAGE and stained with Coomassie Brilliant Blue (CBB) (lanes 1 and 2), immunostained with anti-phosphotyrosine (anti-pY20, lanes 3 and 4), anti-Pan-RAS (lanes 5 and 6), anti-PI3Kinase p85 alpha (lanes 7 and 8), and anti-RAF-Kinase (lanes 9 and 10). Equal numbers of spermatozoa $\left(10^{7}\right.$ cells) were loaded in each lane.

A spectrum of tyrosine polypeptides of $\mathrm{Mr} 19,000$ 99,000 (Figure 5, lane 4) was observed in capacitated total sperm lysate. No bands were detected in the lysates of noncapacitated spermatozoa (Figure 5, lane 3). When the anti-pY20 was preincubated with o-phospho-DL-tyrosine and then used for immunoblotting, no stained bands were observed, suggesting that the polypeptides were specifically phosphorylated on tyrosine residues (data not shown). Blots were subsequently stained with, Coomassie brilliant Blue R (CBB), an identical pattern of CBB-stained polypeptides was 


\section{International Journal of Biochemistry \& Physiology}

exhibited in the lysates of both noncapacitated (Figure 5, lane 1) and capacitated (Figure 5, lane 2) spermatozoa. CBBstained and anti-pY20-stained blots showed that many of the tyrosine-phosphorylated polypeptides are not the major sperm proteins observed by CBB staining. As demonstrated in Figure 5, RAS (lanes 5 and 6), PI3-Kinase (lanes 7 and 8), and RAF-Kinase (lanes 9 and 10) were retained in the sperm pellet before (lanes 5, 7, and 9) and after (lanes 6, 8, and 10) capacitation. RAS and its downstream effectors (PI3-Kinase and RAF-Kinase) were not released during capacitation (data not shown). These results suggest that RAS and its downstream effectors (PI3-Kinase and RAF-Kinase) remain anchored to the sperm pellet/plasma membrane even after the successful completion of capacitation.

\section{Discussion}

Many enzymes and signaling proteins are localized at their sites of function by binding to specific proteins associated with organelles or cytoskeletal elements $[42,43]$. Our biochemical data revealed the localization of FTase $\beta$ to the soluble cell fraction, suggesting that specific barriers may maintain the restricted localization of FTase in spermatozoa. Future studies will address the biochemical localization FTase $\alpha$ in hamster spermatozoa.

RAS may participate in different signaling pathways in spermatozoa, and it is important to identify the upstream and downstream components of the pathways that function in spermatozoa. GTP-RAS binds to and activates several effector molecules, including the serine/threonine RAFKinase, the lipid kinase PI3-Kinase, p120GAP, RalGDS, and

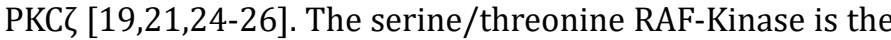
well-characterized downstream effector of RAS in somatic cells $[24,44]$. Two highly conserved domains of RAS termed switch I (amino acids 32-40) and switch II (amino acids 60-72) have been identified as a mediator of the binding of GTP-RAS to its effector proteins [17,45]. Previously, we have shown, by co-immunoprecipitation studies, that RAS interacts with PI3-kinase and PKC $\zeta$ (the downstream effectors of RAS) [26]. In the present study, we demonstrated the presence of GRB2 and RAF-Kinase, which are potential upstream and downstream targets of RAS, respectively, in the plasma membrane fraction of hamster cauda epididymal spermatozoa. In this same study, we showed the localization of RAF-Kinase to the sperm flagellum and connecting piece. Our previous study revealed that RAS is localized to the tail of hamster cauda sperm [26]. Both localization studies strongly suggest a potential functional interaction between RAS and RAF-Kinase. Future immunofluorescence studies will be employed to determine if other potential RAS activators and/or effectors co-localize with RAS. It is possible that these potential activators and effectors localize to a different sperm domain, which would suggest that they function in domain-specific signaling pathways.

With our co-immunoprecipitation analyses, we demonstrate that RAF-Kinase is associated with RAS. We had previously shown that RAS interacts with PI3-kinase and PKC $\zeta$ (the downstream effectors of RAS) [26]. Taken together, these studies reveal the presence of two independent, wellknown RAS downstream signaling pathways in hamster cauda spermatozoa. It has been shown in somatic cells that RAS activates RAF-Kinase, which phosphorylates the MAPK kinase (MEK). In turn, MEK phosphorylates extracellular signal-regulated kinase (ERK) [24]. Future studies will explore the presence of the RAS/RAF/MEK/ERK pathway in hamster cauda epididymal spermatozoa.

After maturation in the epididymis, spermatozoa require residence in the microenvironment of the female tract for a finite period to achieve fertilizing capacity [3,46-49]. This acquisition of functional competence is termed capacitation $[50,51]$. Protein tyrosine phosphorylation is one of the important biochemical mechanisms of sperm capacitation [35-41]. Results from several laboratories regarding the identification of tyrosine-phosphorylated polypeptides during capacitation are contributing to our understanding of the molecular basis of sperm capacitation [32,41,52-56]. In the present study, we have demonstrated that there is no proteolytic processing of RAS and its downstream effectors (PI3-Kinase and RAF-Kinase), and they remain anchored to the sperm pellet/plasma membrane even after the successful completion of capacitation. A future study will address to examine the generation of RAS and its downstream effectors (PI3-Kinase and RAF-Kinase) isoforms during capacitation by two-dimensional PAGE.

The results above suggest the exciting prospect that protein prenylation represents a post-translational mechanism to recruit proteins to specific membrane domains of epididymal sperm. We propose that this posttranslational mechanism may represent a critical step in the development of sperm motility and fertilizing capacity during post-testicular sperm maturation.

Acknowledgements: Supported by NIH grant 5SC3GM125488 (Subir K Nagdas) and NSF grant HRD1436222 (S. Raychoudhury)

\section{References}

1. Eddy EM, O'Brien DA (1994) The Spermatozoon. In: Knobil E, Neill JD (Eds.), The physiology of reproduction. Raven Press: New York, pp: 29-77.

2. Fawcett DW (1975) The mammalian spermatozoon. Dev Biol 44: 394-436. 


\section{International Journal of Biochemistry \& Physiology}

3. Yanagimachi R (1994) Mammalian Fertilization. In: The physiology of reproduction. Raven Press: New York, pp: 189-317.

4. Bartles JR (1995) The spermatid plasma membrane comes of age. Trends Cell Biol 5(10): 400-404.

5. Hinton BT, Palladino MA (1995) Epididymal epithelium: Its contribution to the formation of a luminal fluid microenvironment. Microsc Res Tech 30(1): 67-81.

6. Phelps BM, Koppel DE, Primakoff P, Myles DG (1990) Evidence that proteolysis of the surface is an initial step in the mechanism of formation of sperm cell surface domains. J Cell Biol 111(5): 1839-1847.

7. Petruszak JA, Nehme CL, Bartles JR (1991) Endoproteolytic cleavage in the extracellular domain of the integral plasma membrane protein CE9 precedes its redistribution from the posterior to the anterior tail of the rat spermatozoon during epididymal maturation. J Cell Biol 114(5): 917-927.

8. Casey PJ (1995) Protein lipidation in cell signaling. Science 268(5208): 221-225.

9. Rando RR (1996) Chemical biology of protein isoprenylation/methylation. Biochim Biophys Acta 1300(1): 5-16.

10. Casey PJ, Seabra MC (1996) Protein prenyltransferases. J Biol Chem 271(10): 5289-5292.

11. Zhang FL, Casey PJ (1996) Protein prenylation: molecular mechanisms and functional consequences. Ann Rev Biochem 65: 241-269.

12. Macara IG, Lounsbury KM, Richards SA, McKiernan C, Bar-Sagi D (1996) The Ras superfamily of GTPases. FASEB J 10(5): 625-630.

13. Shen M, Pan P, Li Y, Li D, Yu H, et al. (2015) Farnesyltransferase and geranylgeranyltransferase I: structures, mechanism, inhibitors and molecular modeling. Drug Discov Today 20(2): 267-276.

14. Resh MD (1996) Regulation of cellular signalling by fatty acid acylation and prenylation of signal transduction proteins. Cell Signal 8(6): 403-412.

15. van Corven EJ, Hordijk PL, Medema RH, Bos JL, Moolenaar WH (1993) Pertussis toxin-sensitive activation of p21ras by $\mathrm{G}$ protein-coupled receptor agonists in fibroblasts. Proc Natl Acad Sci U S A 90(4): 1257-1261.

16. Marshall CJ (1996) Ras effectors. Curr Op Cell Biol 8(2): 197-204.
17. Lowy DR, Willumsen BM (1993) Function and regulation of Ras. Ann Rev Biochem 62: 851-891.

18. Katz ME, McCormick R (1997) Signal transduction from multiple Ras effectors. Curr Op Gen Dev 7: 75-79.

19. Zinatizadeh MR, Momeni SA, Zarandi PK, Chalbatani GM, Dana H, et al. (2019) The Role and Function of Rasassociation domain family in Cancer: A Review. Genes Dis 6(4): 378-384.

20. Galiè M (2019) RAS as Supporting Actor in Breast Cancer. Front Oncol 9: 1199.

21. Simanshu DK, Nissley DV, McCormick F (2017) RAS Proteins and Their Regulators in Human Disease. Cell 170(1): 17-33.

22. Wittinghofer A, Herrmann C (1995) Ras-effector interactions, the problem of specificity. FEBS Letters 369(1): 52-56.

23. Diaz-Meco MT, Lozano J, Municio MM, Berra E, Frutos $S$, et al. (1994) Evidence for the in vitro and in vivo interaction of Ras with protein kinase $\mathrm{C}$ z. J Biol Chem 269(50): 31706-31710.

24. Nussinov R, Zhang M, Tsai CJ, Liao TJ, Fushman D, et al. (2018) Autoinhibition in Ras effectors Raf, PI3Ko, and RASSF5: a comprehensive review underscoring the challenges in pharmacological intervention. Biophys Rev 10(5): 1263-1282.

25. Nussinov R, Tsai CJ, Jang H (2019) Does Ras Activate Raf and PI3K Allosterically?. Front Oncol 9: 1231.

26. NagDas SK, Winfrey VP, Olson SE (2002) Identification of Ras and Its Downstream Signaling Elements and Their Potential Role in Hamster Sperm Motility. Biol Reprod 67(4): 1058-1066.

27. Olson GE, Winfrey VP, NagDas SK (1997) Temporal expression and localization of protein farnesyltransferase during spermiogenesis and posttesticular sprm maturation in the hamster. Mol Reprod Dev 48: 71-76.

28. Bradford MM (1976) A rapid and sensitive method for the quantitation of microgram quantities of protein utilizing the principle of protein-dye binding. Anal Biochem 72: 248-254.

29. Laemmli UK (1970) Cleavage of structural proteins during the assembly of the head of bacteriophage T4. Nature 227: 680-685.

30. Fairbanks G, Steck TL, Wallach DFH (1971) Electrophoretic analysis of the major polypeptides of the 


\section{International Journal of Biochemistry \& Physiology}

human erythrocyte membrane. Biochemistry10: 26062617.

31. Towbin H, Staehelin T, Gordon J (1979) Electrophoretic transfer of proteins from polyacrylamide gels to nitrocellulose sheets: Procedure and some applications. Proc Natl Acad Sci 76: 4350-4354.

32. NagDas SK, Winfrey VP, Olson GE (2005) Tyrosine Phosphorylation Generates Multiple Isoforms of the Mitochondrial Capsule Protein, Phospholipid Hydroperoxide Glutathione Peroxidase (PHGPx), During Hamster Sperm Capacitation. Biol Reprod 72(1): 164171.

33. Kopf GS (1990) Zona pellucida-mediated signal transduction in mammalian spermatozoa. J Reprod Fert Suppl 42: 33-49.

34. Ohzu E, Yanagimachi R (1982) Acceleration of acrosome reaction in hamster spermatozoa by lysolecithin. J Exp Zool 224(2): 259-263.

35. Visconti PE, Bailey JL, Moore GD, Pan D, Olds-Clarke P, et al. (1995) Capacitation of mouse spermatozoa. I. Correlation between the capacitation state and protein tyrosine phosphorylation. Development 121(4): 11291137.

36. Pablo E Visconti, Stewart-Savage J, Blasco A, Battaglia L, Miranda P, et al. (1999) Roles of Bicarbonate, cAMP, and Protein Tyrosine Phosphorylation on Capacitation and the Spontaneous Acrosome Reaction of Hamster Sperm. Biol Reprod 61(1): 76-84.

37. Carrera, A., Moos J, Ping Ning P, Gerton GL, Tesarik J, et al. (1996) Regulation of protein tyrosine phosphorylation in human sperm by a calcium/calmodulin-dependent mechanism: identification of A kinase anchor proteins as major substrates for tyrosine phosphorylation. Dev Biol 180: 284-296.

38. Galantino-Homer HL, Visconti PE, Kopf GS (1997) Regulation of protein tyrosine phosphorylation during bovine sperm capacitation by a cyclic adenosine 3', 5'-monophosphate-dependent pathway. Biol Reprod 56(3): 707-719.

39. Emiliozzi C, Fenichel P (1997) Protein tyrosine phosphorylation is associated with capacitation of human sperm in vitro but is not sufficient for its completion. Biol Reprod 56(3): 674-679.

40. Leclerc P, de Lamirande E, Gagnon C (1996) Cyclic adenosine 3',5'monophosphate-dependent regulation of protein tyrosine phosphorylation in relation to human sperm capacitation and motility. Biol Reprod 55(3): 684692.

41. Nagdas SK, Buchanan T, Raychoudhury S (2014) Identification of peroxiredoxin-5 in bovine cauda epididymal sperm. Mol Cell Biochem 387: 113-121.

42. Mochly-Rosen D (1995) Localization of Protein kinases by anchoring proteins: A theme in signal transduction. Science 268(5208): 247-251.

43. Faux MC, Scott JD (1996) More on target with protein phosphorylationL conferring specificity by location. Trends Biochem Sci 21(8): 312-325.

44. Bonni A, Brunet A (1999) Cell survival promoted by the Ras-MAPK signaling pathway by transcriptiondependent and -independent mechanisms. Science 286(5443): 1358-1362.

45. Moodie SA, Paris M, Villafranca E, Kirshmeier P, Willumsen BM, et al. (1995) Different structural requirements within the switch II region of the $\mathrm{Ra}$ protein for interactions with specific downstream targets. Oncogene 11(3): 447-454.

46. Cross NL (1998) Role of Cholesterol in Sperm Capacitation. Biol Reprod 59(1): 7-11.

47. Visconti PE, Kopf GS (1998) Regulation of Protein Phosphorylation during Sperm Capacitation. Biol Reprod 59(1): 1-6.

48. de Lamirande E, Leclerc P, Gagnon C (1997) Capacitation as a regulatory event that primes spermatozoa for the acrosome reaction and fertilization. Mol Hum Reprod 3(3): 175-194.

49. Cohen-Dayag A, Eisenbach M (1994) Potential assays for sperm capacitation in mammals. Am J Physiol Cell Physiol 267(5): C1167-1176.

50. Chang MC (1955) Development of fertilizing capacity of rabbit spermatozoa in the uterus. Nature 175: 10361037.

51. Chang MC (1951) Fertilizing Capacity of spermatozoa deposited into the fallopian tubes. Nature 168(4277): 697-698.

52. Naaby-Hansen S, Mandal A, Wolkowicz MJ, Sen B, Westbrook VA, et al. (2002) CABYR, a novel calciumbinding tyrosine phosphorylation-regulated fibrous sheath protein involved in capacitation. Dev Biol 242(2): 236-254.

53. Ficarro S, Chertihin O, Westbrook VA, White F, Jayes F, 


\section{International Journal of Biochemistry \& Physiology}

et al. (2003) Phosphoproteome analysis of capacitated human sperm. Evidence of tyrosine phosphorylation of a kinase-anchoring protein 3 and valosin-containing protein/p97 during capacitation. J Biol Chem 278(13): 11579-89.

54. Visconti PE, Johnson LR, Oyaski M, Fornés M, Moss SB, et al. (1997) Regulation, localization, and anchoring of protein kinase A subunits during mouse sperm capacitation. Dev Biol 192(2): 351-363.
55. Carrera A, Gerton GL, Moss SB (1994) The major fibrous sheath polypeptide of mouse sperm: structural and functional similarities to the A-kinase anchoring proteins. Dev Biol 165(1): 272-284.

56. Vijayaraghavan S, Goueli SA, Davey MP, Carr DW (1997) Protein kinase A-anchoring inhibitor peptides arrest mammalian sperm motility. J Biol Chem 272(8): 47474752. 